\title{
Community pharmacy Medicines Use Review: current challenges
}

This article was published in the following Dove Press journal: Integrated Pharmacy Research and Practice

\author{
Asam Latif \\ School of Health Sciences, \\ Queen's Medical Centre, \\ The University of Nottingham, \\ Nottingham, UK
}

Correspondence: Asam Latif School of Health Sciences, Queen's Medical Centre, The University of Nottingham, Derby Road, Nottingham NG7 2UH, UK

Tel + 44 I I 58230495

Email asam.latif@nottingham.ac.uk

\begin{abstract}
With a growing aging population, the appropriate, effective, and safe use of medicines is a global health policy priority. One concern is patients' non-adherence to medicines, which is estimated to be up to $50 \%$. Policymakers seek to reconfigure medicine management services and consider community pharmacy as especially well-placed to improve medicine use. In England and Wales, a commissioned medication review service called "Medicines Use Reviews (MURs)" was made available in through the National Health Service (NHS) in 2005. This involves a patient-pharmacist consultation to improve patients' knowledge and the use of medicines and to help reduce avoidable waste. However, over a decade since their introduction, questions remain over the extent to which the MUR policy has successfully been embedded in practice and translated into more effective use of medicines. The MUR intervention continues to hold many challenges ranging from poor public awareness and acceptance of MURs, organizational constraints, and issues over interprofessional collaboration. Many of these challenges are not exclusive to the MUR service, or even to the community pharmacy setting. Nevertheless, by identifying and exposing such challenges, an opportunity exists for policymakers and commissioners to seek to improve this service to patients. This narrative review explores the current challenges that face MURs. Damschroder et al's consolidated framework for implementation research is employed to help organize these challenges from patient and professional perspectives across multiple contexts. Over the past decade, MUR policy and practice has continued to evolve, being shaped by research, organizational and professional influences, and policy. Reforms to the service suggest that the MURs are becoming more responsive to patients' need and preferences. It is intended that this review will create impetus and scope for further debate, service reconfiguration, and ultimately service improvement.
\end{abstract}

Keywords: adherence, community pharmacy, medicines management, Medicines Use Reviews, pharmacist, implementation research, medicines optimization

\section{Introduction}

The English National Health Service (NHS) is funded predominantly through general taxation and by National Insurance contributions and is commonly depicted as being 'free at the point of use'. Many patients are exempted from most medical services and medicine costs, including those aged $<16$ or $\geq 60$ years, as well as those in receipt of state benefits. Alongside other health professionals, community pharmacists are increasingly playing a greater role in the delivery of primary care and progressively feature in global strategies to modernize health care. In England, community pharmacies are classed as independent contractors and are remunerated 
by the NHS for pharmaceutical services. Significant reforms were made to the organization and delivery of community pharmacy services in 2005. A new contractual framework for pharmacy was negotiated and introduced which was built on policy and professional ambitions to improve services to patients, reward for the quality of the services provided, and the harnessing of skills of pharmacists and support staff in addition to providing minimum standards for pharmacy. ${ }^{1}$ This approach differed from the previous community pharmacy contractual arrangements, which primarily focused on remuneration for the volume of prescriptions dispensed. The current pharmacy contract, comprises 3 service levels or "tiers," the first being "essential services" that are offered by all pharmacies (e.g., dispensing of prescriptions, clinical governance requirements, and signposting services). The second tier is "advanced services" (e.g., Medicines Use Reviews [MURs]) that are optional for community pharmacies and typically require pharmacists to undertake additional training before they can be offered. Last, the third tier is contracts for "enhanced services" that are locally commissioned by local authorities, clinical commissioning groups, and the NHS England teams according to the local need. The reforms seen in the new contractual framework were welcomed at the time by pharmacy representative bodies and leaders who have long-held ambitions to shape community pharmacy services for the future. ${ }^{1}$

MURs are an advanced service that has been available since 2005, and are free to patients. It is organized as a one-toone consultation and offered annually, allowing pharmacists the opportunity to hold private and more detailed discussions about the use of patients' medicines, which differ from the limited, brief 'shop floor counseling' interaction that occurs when medicines are supplied. The aim of the service is "with the patient's agreement to improve his or her knowledge and use of drugs." This purpose is to be achieved through the following 4 ways:

1. To establish the patient's actual use, understanding about and experience of taking his or her medications.

2. To identify, discuss, and resolve poor or ineffective use of medicines by the patient.

3. To identify side effects and drug interactions that may affect patient compliance.

4. To improve the clinical and cost-effectiveness of prescribed medicines, thereby reducing the wastage of such drugs. $^{2}$

MURs form part of a wider national medication review agenda that has been defined by the National Institute for Health and Care Excellence as "a structured, critical examination of a person's medicines with the objective of reaching an agreement with the person about treatment, optimising the impact of medicines, minimising the number of medication-related problems and reducing waste." ${ }^{\prime 3}$ The NHS remunerates community pharmacies a fee of $£ 28$ for each review performed by the pharmacist, with the total number each pharmacy contractor is able to claim being subject to a cap of 400 annually. In practice, MURs are a documented patient-pharmacist face-to-face consultation about the patients' medicines use with the underlying aim to "improve his or her knowledge and use of drugs." Patients are eligible for the service if they have been prescribed one or more medicines and are regular users of the pharmacy. Despite the service being available for over a decade, the value, aims, and acceptance of community pharmacy interventions to the public are not always clear. ${ }^{4,5}$ Patients have been found to welcome pharmacists' advice when in line with expected core responsibilities (i.e., dispensing prescriptions/ advice and treatment of minor ailments), but advice is less readily accepted if extended beyond their perceived professional boundaries. ${ }^{6}$ Successful adoption of MURs has been hindered by lack of patient awareness, insufficient integration into existing health care pathways, poor awareness among general practitioners (GPs), and pharmacist workplace barriers. ${ }^{7}$ In this discursive narrative review, the main current challenges to the English MUR service are outlined along with insights into how such challenges may be overcome.

\section{Why are MURs important?}

As well as seeking to improve patients' use of medicines, there are many underlying policy and professional motives that have influenced the development, implementation, and continued commissioning of MURs. There is acknowledgment that with a growing aging demographic, increasing numbers of patients will have long-term medical conditions requiring management with multiple, often expensive medicines. ${ }^{8}$ Mounting concerns have been expressed over patient non-adherence to medicines, estimated to be around $25 \%-50 \% .{ }^{9-11}$ Strategies to deploy the community pharmacy workforce to tackle these long-standing concerns and promote the effective use of medicine are increasingly being sought. ${ }^{12,13}$ This is in the light of pharmacists being perceived as the "experts on medicines" and being more accessible than other professionals due to their extended opening hours and locations in the community. ${ }^{14}$ In addition, services such as the MURs are often viewed as a means for patients to self-manage, care, and so help reduce 
pressures on more expensive secondary or family practice services. ${ }^{15-18}$

Similar community pharmacy medication review services have been commissioned in other countries, suggesting that the value of these services is becoming a priority for many health systems. The forerunner to many of the subsequent services was the Australian Home Medication Review. ${ }^{19}$ This was developed based on views suggesting that there could be improved patient outcomes as well as better use of the professional skills of pharmacists. ${ }^{20}$ Mounting evidence suggests benefits to and acceptance by patients; however, further evidence is needed on clinical outcomes. ${ }^{20}$ In the USA, Medication Therapy Management services exist to optimize therapeutic outcomes through improved medicine adherence and increased patients' understanding of their medicines to reduce possible adverse drug events. ${ }^{21}$ More recently, commissioned services such as the Swiss Polymedication-Check ${ }^{22}$ are being more formally evaluated and have shown to address drug-related problems ${ }^{23}$ and enhance the support of other pharmaceutical services (i.e., weekly pill organizer). ${ }^{24}$ Other medication review services include the Canadian MedsCheck, ${ }^{25}$ New Zealand's MUR, and Italy's MUR. ${ }^{26,27}$

In addition to the economic case for MURs, other psychosocial motives for commissioning MURs are based on a considerable body of evidence that suggests that patients have practical problems in taking medicines. Patients have been shown to be reluctant to take medicines because of concerns about side effects, dependency, or being unclear about their benefits. ${ }^{28,29}$ It has been acknowledged that patients may not feel that physicians have time to discuss and address such concerns. ${ }^{30,31}$ It is envisaged that within their discussions, pharmacist would seek to address patient concerns and empower patients to take a more active role in managing their medicines. MURs undertaken in community pharmacies therefore offer a convenient opportunity to support patient medicine adherence and improve medicine use.

Finally, MURs also embody work that seeks to extend the professional role of pharmacists, improve the relationship with service users, and align with government ambitions to make better use of pharmacists' skills. ${ }^{32,33}$ Long-standing and contemporary "reprofessionalization" of pharmacy aims to move pharmacists' responsibilities away from retail and dispensing, toward patient-centered services such as advice-giving and medicines optimization. ${ }^{34,35}$ Historically, one driver for this shift has been technological advances in large-scale pharmaceutical manufacturing and associated loss of pharmacists' specialized compounding function, ${ }^{36}$ leading to long-standing calls within and outside the profession for pharmacy to consider new roles to help develop and redefine its professional status. ${ }^{37}$ The extent to which pharmacists are able to capitalize on the potential to enhance professional status will be dependent upon how well they are able to compete for legitimacy and jurisdiction, overcome resistance, and navigate current challenges that are faced by MURs and other pharmacy services. ${ }^{38}$

\section{Narrative framework}

Drawing upon Damschroder et al's consolidated framework for implementation research, ${ }^{39}$ the challenges to the MUR service are detailed from patient and professional perspectives as well as across multiple contexts. Damschroder et al's framework is particularly useful in formative evaluations of complex interventions, as it provides a pragmatic structure that unifies key constructs from published implementation theories. ${ }^{40,41}$ The framework is used in this article not to evaluate the service, but to offer policymakers, commissioners, and implementation scientists a systematic analysis that will help to contextualize and organize these challenges.

Damschroder et al's framework consists of 5 areas or "domains." The first examines the characteristics of the intervention itself, in this case, the context in which MURs are delivered, and the role of key stakeholders involved in translating the service in practice. The next two domains consider the "outer" context (wider institutional, political, and social environment within which MURs are implemented) and the "inner" context (organizational structures, cultures, inputs, and resources and the processes and practices that characterize everyday practice and influence implementation). It is acknowledged that the interface between the "inner" and "outer" contexts can be dynamic, and so the lines defining these are not always clear. The fourth domain considers the sense-making, mindsets, cultures, and networks of individuals and groups within the given setting. The final domain cuts across all the above domains to consider the whole implementation process. It is suggested that successful implementation of an intervention usually requires an active change process aimed at achieving individual and organizational level use of the intervention as designed. The current challenges that are faced in the MUR service are detailed and organized below according to this framework. 


\section{MUR challenges}

\section{Domain I: characteristics of MURs and targeting patients who may need them the most}

In the first domain, consideration is given to the MUR intervention itself. Since its inception, there have been several significant reforms to the MUR policy and service delivery, indicating that the service is evolving and the process is responsive to issues and concerns that have emerged following implementation. For example, when introduced, the MUR form that was used to capture patient response was designed as a 'tick box' format that allowed a yes/no response to questions. Information that the pharmacist was expected to elicit from the patient included: 1) patient-reported compliance with the prescribed medicine; 2) whether they knew the medicine's purpose; 3 ) whether the formulation of the medicine was appropriate; 4) whether the medicine was working; and 5) identification of patient-reported side effects. Although it appeared appropriate at the time, following the launch of the service, this format was found to limit opportunities for patient participation and engagement. ${ }^{42}$ It became evident that there was a lack of fit between the intended purposes of creating a patient-centered consultation and professional interpretation of what was required to deliver the service. Reforms to the service in 2011 saw the introduction of a proposed interview schedule for pharmacists, effectively changing the service template to help them shape their conversation with patients. ${ }^{2}$

\section{Box I Medicines Use Review: suggested questions}

1. How are you getting on with your medicines?
2. How do you take or use each of these medicines?
3. Are you having any problems with your medicines or concerns
about taking or using them?
Group by therapeutic areas
4. Do you think they are working? (Prompt: Is this different from
what you were expecting?)
5. Do you think you are getting any side effects or unexpected effects?
6. People often miss taking doses of their medicines, for a wide
range of reasons. Have you missed any doses of your medicine
or changed when you take it? (Prompt: When did you last miss a
dose?)
7. Do you have anything else you would like to know about your
medicines or is there anything you would like me to go over again?
(Prompt: Are you happy with the information you have on your
medicines?)

Note: Reprouduced with permission from Pharmaceutical Services Negotiating Committee (PSNC)/NHS Employers Guidance on the Medicines Use Review Service. 2013. Available from: http://www.nhsemployers.org/ /media/Employers/ Documents/Primary\%20care\%20contracts/Pharmacy/MUR\%20Guidance.pdf. ${ }^{2}$
The new format originated from "proof of concept" work that focused on facilitating adherence to newly prescribed medicines. ${ }^{43}$ This holistic approach aligned with professional ambitions for pharmacists to adopt consultations based upon a shared care approach. ${ }^{33}$ Despite resources being available to improve pharmacists' consultation skills, ${ }^{44}$ the challenge remains to what extent pharmacists are able to internalize and adopt a patient-centered approach within consultations (see "Domain 4: characteristics of stakeholders" section for further details).

Another area that has seen significant development is addressing the question as to who may benefit most from an MUR. There is an overall lack of evidence for the effectiveness of MURs, which hampers any assessment and is a challenge. The most convincing clinical outcomes have been from studies that focus on a particular disease area such as asthma ${ }^{45}$ and coronary heart disease. ${ }^{46}$ Reforms to the national service were introduced in 2011 because of questions over the value of MURs to patients and whether they were being targeted to "local needs and patient priorities." 12 There have been concerns over the significant variability in delivery ${ }^{47}$ and acknowledgement that some patients may benefit from an MUR compared with others. One reason for these concerns was the way in which MURs were reportedly being delivered. The yearly MUR quota that pharmacies are able to undertake (currently 400, originally 200 ) has led to reports that organizations were adopting a commercial "target-driven" organizational approach to delivery over a service that would solely be for patient benefit. ${ }^{48}$ The reforms stipulated the targeting of MURs to patients with specific medical needs. This included patients recently discharged from hospital, patients taking medicines associated with hospital admissions such as nonsteroidal anti-inflammatory drugs, and those prescribed respiratory medicines. ${ }^{49}$ Under these new terms, at least $50 \%$ of all MURs undertaken by the pharmacy should be with patients in these categories. However, there have been issues with these categories, eg, concerns that the uptake of postdischarge MURs has been poor, ${ }^{50}$ despite the potential for medication errors occurring following hospital discharge.${ }^{51}$ When referring to the MUR service, several challenges for health professionals working in secondary care have been identified. Work done by Ramsbottom et al ${ }^{52}$ suggested that national and organizational “"restrictions" placed on MURs may be inhibiting successful adoption. There may be cost-savings if discharge MURs are more widely adopted. ${ }^{53}$ However, there remain challenges including how to make it easier for pharmacists to offer the service to homebound patients, whether carers of patient not 
self-medicating can be offered the opportunity to participate in an MUR, and how to overcome unawareness and lack of patient-expected benefit that has shown to reduce patient engagement. ${ }^{52}$

In addition to identifying those patients who are most in need, there are challenges to identify who could benefit the most and what efforts should be made, if any, to further target the service. There is mounting evidence suggesting that patients belonging to "hard-to-reach" or medically underserved communities (eg, people with disabilities; people from Black, Asian, and Minority Ethnic backgrounds; the homebound; the homeless; and Gypsy, Roma, and Traveller communities) typically experience poorer health outcomes and find accessing health and screening services more difficult when compared to the general population. ${ }^{54-57}$ Marginalized patient groups have been shown to have poorer access to health care because they have been experiencing greater physical barriers and encountering poorer patient-professional communication; consequently, they remain significantly disadvantaged where a service is not tailored to their unique needs or preferences. ${ }^{58}$ There are low levels of evidence to support medication reviews in these populations, principally because they are generally underrepresented in research. ${ }^{59,60}$ Nevertheless, patients from marginalized communities often report poor management of their medical conditions and significant problems with adherence to prescribed medicines. Furthermore, their experience of pharmacy services is found to be variable with many experiencing discrimination or disadvantage as a result of their status. ${ }^{61}$ It is important to note that not all people who may belong to a medically underserved community are the same, and some may not have poorer health when compared to the rest of the population or require additional support to manage medicines. Conversely, people who may have membership to more than one marginalized group may have greater medical needs. One codevelopment approach involving patients who are medically underserved alongside professional stakeholders has sought to raise the awareness of such groups through an online digital, educational intervention aimed directly at frontline pharmacy staff. ${ }^{11}$ In this work, 3 coproduced web-based resources have been developed, namely, 1) discovering and understanding underserved communities; 2) exploring the medicine experiences and needs of patients who are underserved; and 3) effectively interacting and engaging patients who are underserved. Within these resources, practical suggestions on how to effectively engage patients from marginalized communities are provided (the e-learning is freely available online and can be accessed here: http://www.nottingham.ac.uk/helmopen/rlos/pharmacy/ mur-compendium/). The challenge for pharmacy teams is to ensure medicine support is provided in a patient-centered way that is fair and individualized according to the patient circumstance and is also culturally sensitive.

\section{Domain 2: situated outer context}

The second domain considers community pharmacy's position within wider health care structures. Importantly, these also hold significant challenges for pharmacy-led services. This outer context is relevant as research suggests that effective interprofessional collaboration can result in positive patient health outcomes. ${ }^{62,63}$ However, it has been found that GPs hold mixed views about MURs. ${ }^{64,65}$ Poor awareness among GPs and insufficient integration into existing health care pathways have been cited as barriers to effective service implementation. ${ }^{7,48,64}$ GPs' concerns about MURs include the following: pharmacists advising patients during their MURs on clinical matters that the GPs regard as inappropriate, issues over duplication of medication review work, MURs being conducted in isolation, and the potential increase in the workload for the GP that does not directly contribute to their general practice "Quality and Outcomes Framework" contractual measures. ${ }^{7,48}$ Pharmacist-GP relationships have been strained due to the lack of interprofessional engagement, the potential challenge to medical dominance, and changes to the dynamics of existent socially patterned practice. ${ }^{65,66}$ Whereas some of these challenges have yet to be adequately addressed, other administrative areas have seen service improvements. For example, in the beginning, each completed MUR form was sent to the patient's GP. This led to GPs complaining that many MUR forms were unnecessary and the paper format was not compatible with their electronic systems. ${ }^{7,48}$ Changes to the service specification has meant pharmacy contractors are now required to contact the patient's GP only if an issue is identified during the MUR, where the pharmacist believes that the GP should be informed.

The potential of MURs will not fully be realized until there is progress made to improve GP-pharmacist collaboration. ${ }^{67}$ Many obstacles exist including cultural barriers, a lack of clear shared expectations, and lack of routine faceto-face interactions. ${ }^{62}$ Furthermore, there may be underlying resistance from the medical profession to pharmacist role extension. ${ }^{66}$ Other challenges are the geographical separateness or isolation of community pharmacy from general practice and the image of the community pharmacy as a commercial outlet rather than a health care provider. ${ }^{68}$ Despite the challenges and professional boundaries, 
fostering better working relationships between pharmacists and GPs is essential. This, however, has been suggested to involve a "piecemeal" process, ie, one that is slowly built over time and with reliance on the essence of goodwill relationships. ${ }^{65}$ Medicine management organizational policies and practices should be aligned to encourage collective purposive action. In order for deep and sustained change to occur, reforms to the MUR policy to better integrate this within the General Medical Services contractual framework may be needed to encourage pharmacist-GP collaboration for the benefit of the patient.

\section{Domain 3: MUR inner context}

The "“inner" community pharmacy setting in which MURs are performed continues to hold significant challenges to service delivery. As the range of clinical services being offered by the pharmacy increases, early practical challenges of having an appropriate private area to hold private discussions $s^{69,70}$ are been overcome with well-proportioned, purpose-built consultation rooms. However, workload challenges largely remain due to pharmacists spending the majority of their time involved in activities associated with the dispensing of prescriptions. ${ }^{71,72}$ Most MURs have been reported to be pragmatically accommodated into the daily work of the pharmacy without additional pharmacist cover. ${ }^{7,48,73}$ Where there is a lone pharmacist, the effects of their absence may have a greater impact on prescription waiting times and supervision of medicine sales. The pharmacist absence has also been shown to have consequences for pharmacy support staff. ${ }^{74}$

Given the MUR policy remunerates for the volume of MURs undertaken, the balance between organizations setting motivational targets and pharmacists feeling pressurized to perform MURs remains a challenge. ${ }^{7,47,48}$ Inadvertent consequences of this pressure have led to reports of pharmacists inviting patients who they think are on simpler medication regimes that can be performed quickly rather than those patients with more complex regimes who may benefit most. ${ }^{42}$ The pursuit to achieve organizational targets over patient benefit has brought service fidelity into question. It has been suggested that the more quantitative a measure that is used to determine performance, that individuals will seek ways in order to maximize their output; in turn, they may in the process lose sight of what the numbers actually represent. ${ }^{75}$ The challenge, therefore, is how resources can be better managed to ensure that MURs can become part of a comfortable, habitualized, yet nonthreatening, practice.

\section{Domain 4: characteristics of stakeholders}

The fourth domain considers the individuals involved with the intervention and/or implementation process. Most important is the question how well MURs are able to improve patients' knowledge of medicines and their use. From the social science literature, patients' beliefs about medicines and their administration have been shown to be complex. For example, patients have been known to experiment, form impressions, and adjust medicine taking according to their personal health beliefs..$^{29,76}$ They also carry out their own "cost-benefit" analysis based upon "rational" decisions when viewed from their perspectives; these decisions may not always follow medical logic. ${ }^{77}$ Others have suggested that patients' adherence is dependent upon patients' assessment based on a necessity-concerns framework. ${ }^{28}$ Moreover, aversion to medicine taking is widespread, and people quite often only take medicine as a "last resort" and take the perceived minimaleffective dose, despite acknowledging the necessity of their medicine to live as normal a life as possible. ${ }^{78}$ Pharmacists have been known to adopt closed questions, enabling MUR consultations to be completed quickly and efficiently with complex or more indeterminate issues often circumvented. ${ }^{42}$ It, therefore, remains to be seen to what extent pharmacists take the opportunity to uncover, identify, and address such complex health beliefs with the organizational constraints of MUR consultations. Despite initiatives to improve pharmacist consultation skills, ${ }^{44}$ further improvements are needed as it has been found that many adherence intervention studies continue to fail to report tailoring the intervention to patient needs, adopting a shared care assessment or a concordant patient-centered approach. ${ }^{79}$

One further issue has been how the aims of the MUR service are communicated to patients. Studies have attempted to determine whether patients' knowledge of their medicines had improved with positive responses. ${ }^{80}$ Patients in these studies appeared to rate the MUR service highly with reports of the service providing more confidence about their asthma treatment. ${ }^{48}$ Existing perceptions of the pharmacist and the manner in which these are introduced to the patient and are enacted can have significant influence on the way new roles are framed and interpreted by patients. ${ }^{81}$ Despite the range of activities offered by community pharmacists, peoples' perception of pharmacist's role appears to be that of "drugs experts" rather than experts on health and illness. ${ }^{82}$ One reason for this could be the way advanced services are communicated to the public. One study exploring terminologies and how MUR leaflets portrayed and constructed the service 
found a paternalistic theme promoting "patient education" based on the principles of the biomedical model rather than that based on patient empowerment and a concordancecentered approach. ${ }^{83}$ As a consequence, patient framing of such a service may be variegated or conflicting with consequences for patient engagement and sense-making. It is well acknowledged that pharmacists have reported patient engagement with the service to be challenging due to a lack of patient demand, as well as patients being suspicious of the pharmacists' intentions or the pharmacists' inability to communicate the MUR as a useful and relevant service. ${ }^{80}$ Pharmacists have reported feeling rejected and demotivated to arrange MUR appointments where patients have failed to attend, resulting in an "ad hoc" approach to recruitment. ${ }^{48,73}$ Nevertheless, once patients have been engaged, there are suggestions that they have a high level of satisfaction with the service, despite indications that they were initially cautious to become involved. ${ }^{84}$ There may be opportunities for pharmacists to adapt and tailor consultations according to the new approaches to monitoring adherence. This may include calculating adherence to polypharmacy from dispensing data records ${ }^{85}$ or the use of patient self-reports in order to gain an overview of drug-related issues ${ }^{86}$ which may provide added value and a more comprehensive assessment. The challenge for policymakers, educationalists, and professionals is to ensure that pharmacists have the resources, skill sets, and confidence, first, to uncover and address the significant patient concerns with medicines and, second, to convey a service that responds to the needs of patients and patient empowerment and encourages perceptions of pharmacy norms and social conventions.

\section{Domain 5: challenge of implementation}

The final domain "cuts across" all 4 previous domains to consider the process of implementation. On reflection, the evidence for pharmacist-led medication review as an intervention to improve patient health outcomes is still emerging. This may be due to the complexity of capturing data that allow for patient outcomes to be assessed. Difficulties in capturing such data and demonstrating cost-effectiveness may not be solely due to the setting where reviews take place, ${ }^{87}$ but in deficiencies in research methodologies. Positive outcomes of an intervention are often influenced by multiple competing confounders with successful adoption resulting from combining active change processes at individual, interorganizational/ intraorganizational and policy levels..$^{39}$ For example, it is recognized that medication review services vary in their comprehensiveness, minimum competency requirements for pharmacists, levels of interprofessional collaboration, and remuneration. ${ }^{88}$ With regard to MURs, a lack of readiness to change by community pharmacists, a perceived lack of workable strategies to adopt newer roles, and work constraints have been identified and need addressing.$^{89,90}$ Further challenges may include pharmacist negative "personality traits" such as a lack of confidence, paralysis in the face of ambiguity, risk aversion, and need for approval. ${ }^{91}$ Arguably, many of these challenges have largely remained since the inception of the service, and pharmacy teams have been compelled to reshape behaviors and actions to accommodate the service without review of the need for supportive, structural resource or framework.

Despite the barriers, medication review is part of a wider support mechanism and may capture errors or address care deficiencies in a similar manner proposed by Reason's “Swiss cheese model of human error." ${ }^{92}$ In addition to providing opportunities to address medicine adherence issues and other medicine-related problems, MURs can also provide wider benefits including clarification of medicine regimens, initiation of medicines in pill boxes where appropriate, counseling and advice on healthy living, and reassurance that patients are taking medicines correctly. Many facilitators to implementation and practice change have been cited in the literature that may be helpful. These include consultation training to help build pharmacists' confidence, reducing associated administrative work, improved use of pharmacy support staff, and better pharmacy layout and hence workflow. ${ }^{93}$ The way MURs are remunerated can be viewed as a facilitator for MUR activity, but corporate pressure applied to pharmacists has led to negative consequences for patient benefit as outlined above. Other important facilitators could include integrating the MUR service with other medicine management services, ${ }^{62}$ increase in public awareness, and demand for medicine management services, ${ }^{4}$ improved remuneration, and clearer messages from the pharmacy profession itself about the future of professional practice..$^{88}$

\section{Concluding remarks}

Since 2005, reforms to the pharmacy contract have given community pharmacists in England and Wales the opportunity to undertake MURs. This narrative review reflects the personal views and intends to trigger a wider discussion and commentary by others. MURs present an opportunity for pharmacists to broaden their advisory and counseling support to patients through engaging in wider discussions of patient beliefs and concerns about their medicines. MURs also extend both the pharmacists' role and pharmacy's jurisdiction, as it moves from dispensing and advice-giving to monitoring of medicine use, patient education, and intervening to change behaviors. 
Although the MUR offers significant opportunities to support patients with managing comorbidities and complex medicine regimens, this review highlights that many challenges remain to be overcome. The core purpose of what the MUR could potentially offer remains elusive to many patients, and better public communication, pharmacist engagement, and better targeting of MURs to the medically underserved are needed. Other challenges have also been long-standing including investment in workforce, issues of infrastructure, and managing reconfiguration of professional boundaries. In the light of austerity, further work is needed to clearly demonstrate patient outcomes from MURs as well as from other pharmacy medicine management services and their acceptance by patients. In order to further build on existing evidence, ${ }^{94}$ studies should focus on MUR delivery within practice with associated organizational constrains, confounding variables, and acknowledgment of the diversity of stakeholders involved in the process. Current evaluative and research activities within this area are insufficient, and further work needs to be funded and undertaken by researchers and other stakeholders not only to address the challenges presented in this article, but also to highlight the value and potential opportunities that MURs can bring to improving patient outcomes. In the light of the future challenges that pharmacy faces including the individualization of drug treatments, ${ }^{95}$ advancing technological developments, ${ }^{96}$ and emerging roles for pharmacists within general practice, ${ }^{97}$ the opportunities for pharmacists to support patients' medicine taking are significant, and research into these areas and impact on patient care should be a priority.

\section{Acknowledgments}

AL's work is centered on improving the MUR service to people who are medically underserved. His work is funded through the Health Education England and National Institute for Health Research Integrated Clinical Academic Lectureship (HEE / NIHR ICA) Scheme. He declares no other support and no financial relationships with any organizations that might have an interest in the submitted work and no other activities that could appear to have influenced the submitted work.

\section{Disclosure}

The author reports no conflicts of interest in this work.

\section{References}

1. Pharmaceutical Services Negotiating Committee (PSNC). The New Contract for Community Pharmacy. Aylesbury: PSNC; 2004.

2. Pharmaceutical Services Negotiating Committee (PSNC)/NHS Employers Guidance on the Medicines Use Review Service. 2013. Available from: http://www.nhsemployers.org/ /media/Employers/Documents/ Primary\%20care\%20contracts/Pharmacy/MUR\%20Guidance.pdf. Accessed February 6, 2018.
3. National Institute for Health and Care Excellence (NICE) Medicines, and Centre UK Prescribing [webpage on the Internet]. Medicines Optimisation: The Safe and Effective Use of Medicines to Enable the Best Possible Outcomes; 2015. Available from: https://www.nice.org. uk/guidance/ng5. Accessed March 27, 2018.

4. Rodgers RM, Gammie SM, Loo RL, Corlett SA, Krska J. Comparison of pharmacist and public views and experiences of community pharmacy medicines-related services in England. Patient Prefer Adherence. 2016;10:1749-1758.

5. Salter C. Compliance and concordance during domiciliary medication review involving pharmacists and older people. Sociol Health Illn. 2010;32(1):21-36.

6. Eades CE, Ferguson JS, O'Carroll RE. Public health in community pharmacy: a systematic review of pharmacist and consumer views. BMC Public Health. 2011;11:582.

7. Bradley F, Wagner AC, Elvey R, Noyce PR, Ashcroft DM. Determinants of the uptake of medicines use reviews (MURs) by community pharmacies in England: a multi-method study. Health Policy. 2008;88(2-3):258-268.

8. Yap AF, Thirumoorthy T, Kwan YH. Medication adherence in the elderly. J Clin Gerontol Geriatr. 2016;7(2):64-67.

9. Pirmohamed M, James S, Meakin S, et al. Adverse drug reactions as cause of admission to hospital: prospective analysis of 18820 patients. BMJ. 2004;329(7456):15-19.

10. Sabaté E, editor. Adherence to Long-Term Therapies: Evidence for Action. Geneva: World Health Organization; 2003.

11. DiMatteo MR. Variations in patients' adherence to medical recommendations: a quantitative review of 50 years of research. Med Care. 2004;42(3):200-209.

12. Department of Health. Pharmacy in England: Building on StrengthsDelivering the Future. 2008. Available from: https://www.gov.uk/government/uploads/system/uploads/attachment_data/file/228858/7341. pdf. Accessed February 6, 2018.

13. Royal Pharmaceutical Society. Medicines Optimisation: Helping Patients to Make the Most of Medicines. London: Royal Pharmaceutical Society; 2013. Available from: www.rpharms.com/promotingpharmacy-pdfs/helping-patients-make-the-most-of-their-medicines. pdf. Accessed February 6, 2018.

14. Todd A, Copeland A, Husband A, Kasim A, Bambra C. The positive pharmacy care law: an area-level analysis of the relationship between community pharmacy distribution, urbanity and social deprivation in England. BMJ Open. 2014;4(8):e005764.

15. Imison C, Sonola L, Honeyman M, Ross S. The Reconfiguration of Clinical Services: What is the Evidence? King's Fund; London: 2014.

16. Hatah E, Braund R, Tordoff J, Duffull SB. A systematic review and meta-analysis of pharmacist-led fee-for-services medication review. Br J Clin Pharmacol. 2014;77(1):102-115.

17. Bulajeva A, Labberton L, Leikola S, et al. Medication review practices in European countries. Res Social Adm Pharm. 2014;10(5): 731-740.

18. Rutter P. Role of community pharmacists in patients' self-care and self-medication. Integr Pharm Res Pract. 2015;4:57-65.

19. Jokanovic N, Tan EC, van den Bosch D, Kirkpatrick CM, Dooley MJ, Bell JS. Clinical medication review in Australia: a systematic review. Res Social Adm Pharm. 2016;12(3):384-418.

20. Chen TF. Pharmacist-led home medicines review and residential medication management review: the Australian model. Drugs Aging. 2016;33(3):199-204.

21. Barnett M, Frank J, Wehring H, et al. Analysis of pharmacist-provided medication therapy management (MTM) services in community pharmacies over 7 years. J Manag Care Pharm. 2009;15(1):18-31.

22. Niquille A, Lattmann C, Bugnon O. Medication reviews led by community pharmacists in Switzerland: a qualitative survey to evaluate barriers and facilitators. Pharm Pract (Granada). 2010;8(1):35-42.

23. Messerli M, Blozik E, Vriends N, Hersberger KE. Impact of a community pharmacist-led medication review on medicines use in patients on polypharmacy - a prospective randomised controlled trial. $B M C$ Health Serv Res. 2016;16:145. 
24. Hersberger KE, Messerli M. Development of clinical pharmacy in Switzerland: involvement of community pharmacists in care for older patients. Drugs Aging. 2016;33(3):205-211.

25. Dolovich L, Consiglio G, MacKeigan L, et al. Uptake of the MedsCheck annual medication review service in Ontario community pharmacies between 2007 and 2013. Can Pharm J (Ott). 2016;149(5):293-302.

26. Lee E, Braund R, Tordoff J. Examining the first year of Medicines Use Review services provided by pharmacists in New Zealand: 2008. NZ Med J. 2009;122(1293):3566.

27. Manfrin A, Tinelli M, Thomas T, Krska J. A cluster randomised control trial to evaluate the effectiveness and cost-effectiveness of the Italian medicines use review (I-MUR) for asthma patients. BMC Health Serv Res. 2017;17(1):300.

28. Horne R, Chapman SC, Parham R, Freemantle N, Forbes A, Cooper V. Understanding patients' adherence-related beliefs about medicines prescribed for long-term conditions: a meta-analytic review of the Necessity-Concerns Framework. PLoS One. 2013;8(12):e80633.

29. Pound P, Britten N, Morgan M, et al. Resisting medicines: a synthesis of qualitative studies of medicine taking. Soc Sci Med. 2005;61(1): 133-155.

30. Moen J, Bohm A, Tillenius T, Antonov K, Nilsson JL, Ring L. “I don't know how many of these [medicines] are necessary" - a focus group study among elderly users of multiple medicines. Patient Educ Couns 2009;74(2):135-141

31. Dugdale DC, Epstein R, Pantilat SZ. Time and the patient-physician relationship. J Gen Intern Med. 1999;14(Suppl 1):S34-S40.

32. McDonald R, Cheraghi-Sohi S, Sanders C, Ashcroft D. Professional status in a changing world: the case of medicines use reviews in English community pharmacy. Soc Sci Med. 2010;71(3):451-458.

33. Smith J, Picton C, Dayan M. Now More Than Ever. Nuffield Trust; 2014. Available from: https://www.nuffieldtrust.org.uk/files/2017-01/ now-more-than-ever-web-final.pdf. Accessed February 6, 2018.

34. Birenbaum A. Reprofessionalization in pharmacy. Soc Sci Med. 1982;16(8):871-878.

35. Mossialos E, Courtin E, Naci H, et al. From "retailers" to health care providers: transforming the role of community pharmacists in chronic disease management. Health Policy. 2015;119(5):628-639.

36. Harding G, Taylor K. Responding to change: the case of community pharmacy in Great Britain. Sociol Health Illn. 1997;19(5):547-560.

37. Cipolle RJ, Strand LM, Morley PC. Pharmaceutical Care Practice: the Patient-Centered Approach to Medication Management. New York: McGraw Hill Professional; 2012.

38. Waring J, Latif A. Of shepherds, sheep and sheepdogs? Governing the adherent self through complementary and competing 'pastorates'. Sociology. 2017. In press.

39. Damschroder LJ, Aron DC, Keith RE, Kirsh SR, Alexander JA, Lowery JC. Fostering implementation of health services research findings into practice: a consolidated framework for advancing implementation science. Implement Sci. 2009;4:50.

40. May C, Finch T, Mair F, et al. Understanding the implementation of complex interventions in health care: the normalization process model. BMC Health Serv Res. 2007;7:148.

41. Greenhalgh T, Robert G, Macfarlane F, Bate P, Kyriakidou O. Diffusion of innovations in service organizations: systematic review and recommendations. Milbank Q. 2004;82(4):581-629.

42. Latif A, Pollock K, Boardman HF. The contribution of the Medicines Use Review (MUR) consultation to counseling practice in community pharmacies. Patient Educ Couns. 2011;83(3):336-344.

43. Clifford S, Barber N, Elliott R, Hartley E, Horne R. Patient-centred advice is effective in improving adherence to medicines. Pharm World Sci. 2006;28(3):165-170.

44. Jee S, Grimes L, Desborough J, Cutts C. The national consultation skills for pharmacy practice program in England. Curr Pharm Teach Learn. 2016;8(3):442-446.

45. Portlock J, Holden M, Patel S. A community pharmacy medicines use review service in Hampshire and the Isle of Wight. Pharm J. 2009;282:109-112.
46. Wilcock M, Harding G. What do pharmacists think of MURs and do they change prescribed medication? Pharm J. 2008;280:163-167.

47. Harding G, Wilcock M. Community pharmacists' perceptions of medicines use reviews and quality assurance by peer review. Pharm World Sci. 2010;32(3):381-385.

48. Blenkinsopp A, Bond C, Celino G, Inch J, Gray N. National Evaluation of the New Community Pharmacy Contract. Pharmacy Practice Research Trust; London: 2007.

49. Pharmaceutical Services Negotiating Committee (PSNC) [webpage on the Internet]. National Target Groups for MURs. 2017. Available from: http://psnc.org.uk/services-commissioning/advanced-services/murs/ national-target-groups-for-murs/. Accessed February 6, 2018.

50. Royal Pharmaceutical Society. Keeping Patients Safe When They Transfer Between Care Providers-Getting the Medicines Right. Individual Reports from the Early Adopter Sites. RPS; 2012. Available from: https:// www.rpharms.com/Portals/0/RPS\%20document $\% 20$ library/Open $\% 20$ access/Publications/Keeping\%20patients\%20safe $\% 20$ transfer $\% 20$ of\%20care\%20report.pdf. Accessed February 6, 2018.

51. Vira T, Colquhoun M, Etchells E. Reconcilable differences: correcting medication errors at hospital admission and discharge. Qual Saf Health Care. 2006;15(2):122-126.

52. Ramsbottom HF, Fitzpatrick R, Rutter P. Post discharge medicines use review service for older patients: recruitment issues in a feasibility study. Int J Clin Pharm. 2016;38(2):208-212.

53. Ramsbottom H, Rutter P, Fitzpatrick R. Post discharge medicines use review (dMUR) service for older patients: cost-savings from community pharmacist interventions. Res Social Adm Pharm. 2018;14(2);203-206.

54. The Disability Partnership. Evaluation Report of the 2015-16 Mencapled Pharmacy Project. 2016. Available from: https://www.mencap.org. uk/sites/default/files/2016-07/Mencap_DP_Pharmacy_report_v1.pdf. Accessed February 6, 2018.

55. Qiu WQ, Dean M, Liu T, et al. Physical and mental health of homebound older adults: an overlooked population. J Am Geriatr Soc. 2010;58(12):2423-2428.

56. Aspinall P [webpage on the Internet]. Hidden Needs. Identifying Key Vulnerable Groups in Data Collections: Vulnerable Migrants, Gypsies and Travellers, Homeless People, and Sex Workers. Inclusion Health; 2014. Available from: https://www.scie-socialcareonline.org.uk/ hidden-needs-identifying-key-vulnerable-groups-in-data-collectionsvulnerable-migrants-gypsies-and-travellers-homeless-people-and-sexworkers/r/a11G0000003E7TeIAK. Accessed February 6, 2018.

57. Evandrou M, Falkingham J, Feng Z, Vlachantoni A. Ethnic inequalities in limiting health and self-reported health in later life revisited. $J$ Epidemiol Community Health. 2016;70(7):653-662.

58. Healy J, McKee M. Accessing Health Care: Responding to Diversity. London: Oxford University Press; 2004.

59. Latif A, Pollock K, Anderson C, et al. Supporting underserved patients with their medicines: a study protocol for a patient/professional coproduced education intervention for community pharmacy staff to improve the provision and delivery of Medicine Use Reviews (MURs). BMJ Open. 2016;6(12):e013500.

60. Bonevski B, Randell M, Paul C, et al. Reaching the hard-to-reach: a systematic review of strategies for improving health and medical research with socially disadvantaged groups. BMC Med Res Methodol. 2014;14:42.

61. Latif A, Tariq S, Abbasi N, Mandane B. Giving voice to the medically under-served: a qualitative co-production approach to explore patient medicine experiences and improve services to marginalized communities. Pharmacy (Basel). 2018;6(1):pii:E13.

62. Chen TF, de Almeida Neto AC. Exploring elements of interprofessional collaboration between pharmacists and physicians in medication review. Pharm World Sci. 2007;29(6):574-576.

63. Avery AJ, Rodgers S, Cantrill JA, et al. A pharmacist-led information technology intervention for medication errors (PINCER): a multicentre, cluster randomised, controlled trial and cost-effectiveness analysis. Lancet. 2012;379(9823):1310-1319.

64. Wilcock, M. Harding, G. General practitioners' perceptions of medicines use reviews by pharmacists. Pharm J. 2007;279:501-503. 
65. Bradley F, Elvey R, Ashcroft DM, et al. The challenge of integrating community pharmacists into the primary health care team: a case study of local pharmaceutical services (LPS) pilots and interprofessional collaboration. J Interprof Care. 2008;22(4):387-398.

66. Edmunds J, Calnan MW. The reprofessionalisation of community pharmacy? An exploration of attitudes to extended roles for community pharmacists amongst pharmacists and General Practitioners in the United Kingdom. Soc Sci Med. 2001;53(7):943-955.

67. Latif A, Pollock K, Boardman HF. Medicines use reviews: a potential resource or lost opportunity for general practice? BMC Fam Pract. 2013;14(1):57.

68. Hughes CM, McCann S. Perceived interprofessional barriers between community pharmacists and general practitioners: a qualitative assessment. Br J Gen Pract. 2003;53(493):600-606.

69. Latif A, Boardman H. Community pharmacists' attitudes towards medicines use reviews and factors affecting the numbers performed. Pharm World Sci. 2008;30(5):536-543.

70. Rapport F, Doel MA, Jerzembek GS. "Convenient space" or "a tight squeeze": insider views on the community pharmacy. Health Place. 2009;15(1):315-322.

71. Hassell K, Seston EM, Schafheutle EI, Wagner A, Eden M. Workload in community pharmacies in the UK and its impact on patient safety and pharmacists' well-being: a review of the evidence. Health Soc Care Community. 2011;19(6):561-575.

72. Lea VM, Corlett SA, Rodgers RM. Workload and its impact on community pharmacists' job satisfaction and stress: a review of the literature. Int J of Pharm Pract. 2012;20(4):259-271.

73. Urban R, Rivers P, Morgan J. Perceptions of medicines use reviews - the views of community pharmacists within a West Yorkshire primary care trust. Pharm J. 2008;281:303-305.

74. Latif A, Boardman HF, Pollock K. A qualitative study exploring the impact and consequence of the medicines use review service on pharmacy support-staff. Pharm Pract (Granada). 2013;11(2):118-124.

75. Moyo M. When good pharmacists do less-than-good things. Pharm J. 2010;285:403.

76. Banning M. Older people and adherence with medication: a review of the literature. Int J Nurs Stud. 2008;45(10):1550-1561.

77. Donovan JL, Blake DR. Patient non-compliance: deviance or reasoned decision-making? Soc Sci Med. 1992;34(5):507-513.

78. Townsend A, Hunt K, Wyke S. Managing multiple morbidity in mid-life: a qualitative study of attitudes to drug use. BMJ. 2003;327(7419):837.

79. Andersson M, Garfield S, Eliasson L, Jackson C, Raynor DK. Delivery of patient adherence support: a systematic review of the role of pharmacists and doctors. Patient Intell. 2014;6:31-42.

80. Latif A, Boardman HF, Pollock K. Understanding the patient perspective of the English community pharmacy Medicines Use Review (MUR). Res Social Adm Pharm. 2013;9(6):949-957.

81. Latif A, Waring J, Watmough D, Boyd MJ, Elliott RA. "I expected just to walk in, get my tablets and then walk out": on framing new community pharmacy services in the English healthcare system. Sociol Health Ill. 2018. In press.
82. Anderson C, Blenkinsopp A, Armstrong M. Feedback from community pharmacy users on the contribution of community pharmacy to improving the public's health: a systematic review of the peer reviewed and non-peer reviewed literature 1990-2002. Health Expect. 2004;7(3): 191-202.

83. van den Berg M, Donyai P. How was patient empowerment portrayed in information leaflets describing the community pharmacy Medicines Use Review service in the UK? Patient Educ Couns. 2010;80(2): 274-276.

84. Hindi A, Parkhurst C, Rashidi Y, Ho SY, Patel N, Donyai P. Development and utilization of the Medicines Use Review patient satisfaction questionnaire. Patient Prefer Adherence. 2017;11:1797-1806.

85. Arnet I, Abraham I, Messerli M, Hersberger KE. A method for calculating adherence to polypharmacy from dispensing data records. Int $J$ Clin Pharm. 2014;36(1):192-201.

86. Messerli M, Aschwanden R, Buslau M, Hersberger KE, Arnet I. Swallowing difficulties with medication intake assessed with a novel selfreport questionnaire in patients with systemic sclerosis-a cross-sectional population study. Patient Prefer Adherence. 2017;11:1687-1699.

87. Hohl CM, Wickham ME, Sobolev B, et al. The effect of early in-hospital medication review on health outcomes: a systematic review. Br J Clin Pharmacol. 2015;80(1):51-61.

88. Roberts AS, Benrimoj SI, Chen TF, Williams KA, Aslani P. Implementing cognitive services in community pharmacy: a review of facilitators used in practice change. Int J Pharm Pract. 2006;14(3):163-170.

89. Bryant LJ, Coster G, Gamble GD, McCormick RN. General practitioners' and pharmacists' perceptions of the role of community pharmacists in delivering clinical services. Res Social Adm Pharm. 2009;5(4):347-362.

90. Farris KB, Schopflocher DP. Between intention and behavior: an application of community pharmacists' assessment of pharmaceutical care. Soc Sci Med. 1999;49(1):55-66.

91. Rosenthal M, Austin Z, Tsuyuki RT. Are pharmacists the ultimate barrier to pharmacy practice change? Can Pharm J. 2010;143(1):37-42.

92. Reason J. Human error: models and management. BMJ. 2000;320(7237): 768-770.

93. Gastelurrutia MA, Benrimoj SC, Castrillon CC, de Amezua MJ, Fernandez-Llimos F, Faus MJ. Facilitators for practice change in Spanish community pharmacy. Pharm World Sci. 2009;31(1):32-39.

94. Perraudin C, Bugnon O, Pelletier-Fleury N. Expanding professional pharmacy services in European community setting: is it cost-effective? A systematic review for health policy considerations. Health Policy. 2016;120(12):1350-1362.

95. Denford S, Frost J, Dieppe P, Cooper C, Britten N. Individualisation of drug treatments for patients with long-term conditions: a review of concepts. BMJ Open. 2014;4(3):e004172.

96. Elhassan GO, Hashmi S, Farhana SA, Qureshi KA, Khan RA. Role of pharmacists in pharmacogenomics. J Pharmacovigil. 2017;5:3.

97. Tan EC, Stewart K, Elliott RA, George J. Pharmacist services provided in general practice clinics: a systematic review and meta-analysis. Res Social Adm Pharm. 2014;10(4):608-622.
Integrated Pharmacy Research and Practice

\section{Publish your work in this journal}

Integrated Pharmacy Research and Practice is an international, peer-reviewed, open access, online journal, publishing original research, reports, reviews and commentaries on all areas of academic and professional pharmacy practice. This journal aims to represent the academic output of pharmacists and pharmacy practice with particular focus on integrated care. All papers are carefully

\section{Dovepress}

peer reviewed to ensure the highest standards as well as ensuring that we are informing and stimulating pharmaceutical professionals. The manuscript management system is completely online and includes a very quick and fair peer-review system, which is all easy to use. Visit http://www.dovepress.com testimonials.php to read real quotes from published authors. 